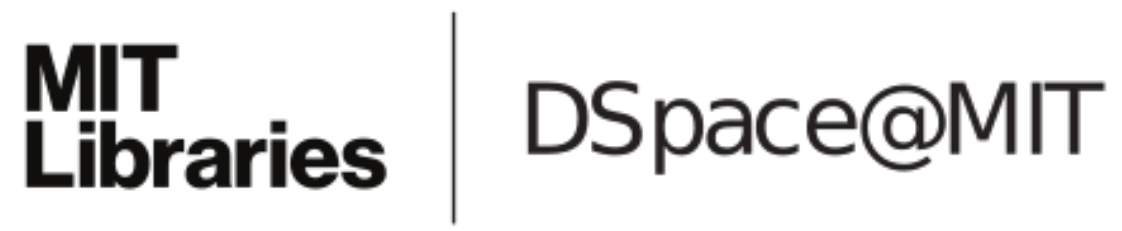

\author{
MIT Open Access Articles
}

PSD-95-like membrane associated guanylate kinases (PSD-MAGUKs) and synaptic plasticity

The MIT Faculty has made this article openly available. Please share how this access benefits you. Your story matters.

Citation: Xu, Weifeng. "PSD-95-like Membrane Associated Guanylate Kinases (PSD-MAGUKs) and Synaptic Plasticity." Current Opinion in Neurobiology 21, no. 2 (April 2011): 306-12.

As Published: http://dx.doi.org/10.1016/j.conb.2011.03.001

Publisher: Elsevier

Persistent URL: http://hdl.handle.net/1721.1/98845

Version: Author's final manuscript: final author's manuscript post peer review, without publisher's formatting or copy editing

Terms of use: Creative Commons Attribution-Noncommercial-NoDerivatives 


\title{
PSD-95-like membrane associated guanylate kinases (PSD- MAGUKs) and Synaptic Plasticity
}

\author{
Weifeng Xu \\ Picower Institute for Learning and Memory, Department of Brain and Cognitive Sciences, \\ Massachusetts Institute of Technology, 77 Massachusetts Ave. Cambridge, MA 02319
}

\begin{abstract}
Activity-dependent modification of excitatory synaptic transmission is fundamental for developmental plasticity of the neural circuits and experience-dependent plasticity. Synaptic glutamatergic receptors including AMPA receptors and NMDA receptors (AMPARs and NMDARs) are embedded in the highly organized protein network in the postsynaptic density. Overwhelming data have shown that PSD-95-like membrane associated guanylate kinases (PSDMAGUKs), as a major family of scaffold proteins at glutamatergic synapses, regulate basal synaptic AMPAR function and trafficking. It is now clear that PSD-MAGUKs have multifaceted functions in terms of regulating synaptic transmission and plasticity. Here we discuss recent advancements in understanding the roles of PSD-95 and other family members of PSD-MAGUKs in synaptic plasticity, both as an anchoring protein for synaptic AMPARs and also as a signaling scaffold for mediating the interaction of the signaling complex and NMDARs.
\end{abstract}

\section{Introduction}

PSD-95-like membrane associated guanylate kinases (PSD-MAGUKs) conform a major family of multidomain scaffold proteins at glutamatergic synapses, including PSD-95 (SAP90), PSD-93 (Chapsyn-110), SAP102 and SAP97. They are multi-modular proteins sharing the common domain structure composed of three PSD-95/Discs large/zona occludens-1 (PDZ) domains, followed by a Src-homology-3 (SH3) domain and a catalytically inactive guanylate kinase (GK) domain. They interact with a variety of membrane proteins including ionotropic glutamate receptors, ion channels, neuromodulartory receptors, cell-adhesion molecules. PSD-MAGUKs also interact with intracellular proteins including other scaffold proteins, actin cytoskeleton components and signaling proteins [1] [2] [3]. Among the family members, expression of PSD-95 and PSD-93 has been shown to be dysregulated in neuropsychiatric patients [4], and loss of function mutations in the SAP102 gene cause nonsyndromic X-linked mental retardation [5]. Furthermore, within the array of interaction partners, several were identified in genetic studies of neuropsychiatric and neurodevelopmental disorders, including neuroligins in autism spectrum disorder [6], SAPAP3 in obsessive compulsive disorder [7], and its interaction partner SHANK family proteins in ASD [8] [9], poising PSD-MAGUKs a central role in orchestrating normal synaptic function at glutamatergic synapses. Here I focus on the

(C) 2011 Elsevier Ltd. All rights reserved.

Corresponding author: Weifeng Xu (weifeng@mit.edu).

Publisher's Disclaimer: This is a PDF file of an unedited manuscript that has been accepted for publication. As a service to our customers we are providing this early version of the manuscript. The manuscript will undergo copyediting, typesetting, and review of the resulting proof before it is published in its final citable form. Please note that during the production process errors may be discovered which could affect the content, and all legal disclaimers that apply to the journal pertain. 
recent studies exploring the possible roles of PSD-MAGUK in synaptic plasticity, and discuss several prevalent hypotheses.

\section{PSD-95 and synaptic plasticity}

Among the four PSD-MAGUKs family members, PSD-95 is the most extensively studied in the context of synaptic plasticity. It is highly enriched in the PSD [10] and has been proposed to play an essential role for maintaining and regulating synaptic AMPAR function [11**]. In vivo studies have shown that activity-dependent redistribution of PSD-95 in visual cortex correlates with eye opening [12], and is thought to be involved in the control of developmental plasticity [13]. PSD-mutant mice exhibit a variety of behavioral deficits including learning deficit, drug addiction, suggesting its involvement in experiencedependent plasticity [14*] [15]. I will first discuss the studies focusing on the role of PSD-95 in regulating NMDAR-dependent synaptic plasticity. Then in the later part of the review, I will discuss the functional diversity with other PSD-MAGUKs, and their possible roles in other types of plasticity (summarized in Figure 1).

Given the central role of PSD-95 in scaffolding the ionotrophic glutamate receptors, intracellular cytoskeleton components and signaling adaptors, two major hypotheses for how PSD-95 regulates NMDAR-dependent synaptic plasticity are generated (1), as slot proteins for AMPARs, PSD-95 acts as the target of the signaling during plasticity, in that changes in the levels of PSD-95 directly influence the levels of synaptic AMPAR. (2), as a signaling scaffold, that bring intracellular signaling complexes close to NMDAR channels. In other words, PSD-95 bridges the calcium influx to the specific downstream signaling events.

Experimental work using genetically modified animals, overexpression, acute knockdown and molecular replacement strategies has provided strong evidence supporting the role of PSD-95 in controlling basal synaptic AMPAR levels [11]. Briefly, the levels of PSD-95 are directly correlated with the size of AMPAR-mediated excitatory postsynaptic currents (APMAR EPSCs). Overexpression of PSD-95 enhances and acute knockdown of PSD-95 decreases synaptic AMPAR EPSCs. While some studies in PSD-95 mutant mice showed lack of effect on basal synaptic transmission [16] [14*], others showed AMPAR-mediated response is decreased at certain developmental stages, presumably due to the changes of other PSD-MAGUK during development [17] [18**]. In PSD-95 mutant mice, LTP was greatly enhanced, whereas LTD is absent. Consistent with these results, acute knockdown of PSD-95 blocked or decreased LTD [19**] [20]; whereas overexpression of PSD-95 occluded LTP and decreased the threshold for LTD induction [21] [22]. These data strongly suggest the involvement of PSD-95 in synaptic plasticity; in particular, PSD-95 may be indispensible for NMDAR-dependent LTD.

\section{NMDAR-dependent LTD, slot hypothesis of PSD-95}

It has been hypothesized that PSD-95 may act as a "slot" protein for synaptic AMPARs with the concentration of PSD-95 at the synapse regulating synaptic AMPAR levels [23] [24]. In this scenario, PSD-95 would be a target of the LTD signaling cascade and the reduction of synaptic PSD-95 would lead to the loss of synaptic AMPARs. Data supporting this scenario first came from studies of agonist-induced AMPAR endocytosis in dissociated neuron culture. It has been reported that synaptic PSD-95 levels can be dynamically regulated via palmitoylation and ubiquitination, and thereby influence synaptic AMPAR levels upon agonist stimulation $\left[24^{*}, 25^{*}\right]$. College et al (2003) showed that NMDA treatment of dissociated cultures induced polyubiquitination of PSD-95 that directed PSD-95 to the proteasomal degradation. The effect of ubiquitination of PSD-95 on synaptically induced LTD has not been directly tested. Another study suggested that PSD-95 could be palmitoylated at the $\mathrm{N}$-terminal region [25*]. Palmitoylation is a reversible lipid 
modification process to the target protein, which will direct the protein to associate with the cell membrane and thought to be involved in protein trafficking and signaling pathways important for brain development and synaptic transmission [26]. PSD-95 in the PSD is highly palmitoylated, and glutamate treatment of dissociated culture induces depalmitoylation of PSD-95 leading to the diffusion of PSD-95 out of the synapses, accompanied by decreased synaptic AMPAR content [25*]. However, it has been shown that membrane detachment of PSD-95 is not crucial for mediating synaptically induced LTD, suggesting that this pathway may not be directly involved in the induction of LTD, but likely contributing to other types of activity-dependent regulation of synaptic strength. A recent study identified that a Rac1-JNK signaling pathway mediates phosphorylation of S295 residue in PSD-95, which regulates synaptic content of PSD-95 [27]. S295 phosphorylation promotes synaptic accumulation of PSD-95 and influences synaptic potentiation. NMDA treatment (culture model of LTD) decreases S295 phosphorylation, whereas the chemical-induced LTP (chemLTP) stimulation increases S295 phosphorylation. Moreover, overexpression of the mutant mimicking phosophorylation (S295D) blocks AMPAR internalization and synaptically induced LTD. NMDA treatment decreases the levels of S295 phosphorylation. S295A mutant that cannot be phosphorylated is less effective in terms of synaptic accumulation of PSD-95 and enhancement of synaptic GluR1 content, and is permissive for LTD. These data suggest that dephosphorylation of S295 is necessary for LTD induction and/or expression presumably by regulating synaptic PSD-95 levels [27*]. Thus at least three different types of activity-dependent post-translational modification of PSD-95 can be used for regulating synaptic PSD-95 levels, hence synaptic anchoring slots for AMPARs for the expression of LTD.

\section{NMDAR-dependent LTD, signaling scaffold hypothesis of PSD-95}

As a multimodular protein, PSD-MAGUKs interact with an array of intracellular proteins that have been implicated in synaptic plasticity. Studies on PSD-95 mutant mice suggested that PSD-95 is essential for mediating LTD. Using a molecular replacement strategy, studies have shown that the effects of PSD-95 on regulating basal synaptic AMPAR function and mediating LTD can be dissociated [19**]. The SH3-GK domain of PSD-95, which interacts with AKAP79/150 is suggested to be critical for the expression of LTD at hippocampal Shaffer-collateral CA1 synapses. Furthermore, the stability of PSD-95 is presumably crucial for the LTD. PSD-95 is a relatively stable component in the PSD [28] [29*]. Mutants that exhibit faster diffusion kinetics block LTD, and a double mutant that rescues the diffusion kinetics rescues LTD as well [19**]. It has been shown that the interactions of AKAP79/150 with the downstream protein kinases and phosphatase are important for NMDAR-dependent LTD [30-33]. PSD-95 is proposed to facilitate PP2B activation by positioning the associated signaling complex close to the site of calcium influx through NMDARs, presumably via AKAP79/150-PSD-95 interaction. The tri-partner interaction among PSD-95, AKAP79/150 and PP2B is likely highly dynamic and tightly regulated during LTD induction, but the precise interaction dynamics during LTD remain unclear. Nevertheless, lack of PSD-95, destabilizing mutants, and mutants disrupting the intracellular interaction with AKAP79/150 all disrupt LTD, presumably by de-coupling synaptic NMDARs from the LTD signaling cascade [19**]. These evidences suggest a role of PSD-95 as a signaling scaffold for LTD.

Combining the two lines of evidences, it is conceivable to hypothesize that PSD-95 is involved in LTD in two stages, first, as a signaling scaffold that mediates the dynamic interactions involved in the signaling events during the LTD induction phase; second, as the AMPARs anchoring protein in the PSD, is down-regulated via different mechanisms to maintain the decreased synaptic AMPAR content at the expression phase of LTD. The decrease of PSD-95 levels can thus also serve as a brake for the LTD signaling events. 


\section{NMDAR-dependent LTP}

Data from PSD-95 mutant animals and overexpression studies suggest that PSD-95 is a negative regulator of NMDAR-dependent LTP [14*] [21]. Acute knockdown studies showed that the induction of synaptic LTP is not affected by the lack of PSD-95, whereas spine growth (structural plasticity) is impaired [20] [29*], suggesting the different contribution of PSD-95 in regulating structural and functional LTP. It has been shown that S295 of PSD-95 can be dephosphorylated with the chemLTP protocol [27*], but whether this process contributes to LTP induction and expression has not been explored. Another study has shown that the diffusion dynamics of PSD-95 can be increased by CaMKII activity during the LTP induction phase likely through phosphorylation of Serine residue at position 73 (S73) [29*]. The phosphomimetic mutant (S73D) destabilizes the PSD and inhibits activity-dependent spine growth and synaptic potentiation. This line of evidence suggests that the stability of PSD-95 during the initial phase of LTP is important for the spine growth and expression of LTP, and the phosphorylation of PSD-95 at S73 is likely a limiting factor for structural and functional postsynaptic potentiation. It is worthwhile to notice that S73A (non-phosphorylatable mutant) and S73D mutants have similar effect on enhancing synaptic AMPAR levels to that of wild-type of PSD-95, suggesting that the effect on basal transmission and the involvement of PSD-95 in regulating structural and functional plasticity are in principle, separable. The degrees of LTP in both wild-type and S73A (stable) overexpression cases are significantly less compared to GFP control, in line with the evidence from mutant animals that PSD-95 a negative regulator of functional LTP, whereas S73D (less stable) overexpression completely blocks functional LTP. These evidences suggest that the dynamics of PSD-95 has to be temporally tightly regulated, to establish the sequential events for the expression of LTP.

\section{Plasticity of NMDAR}

Recent studies suggest that PSD-95 is involved in muscarinic acetylcholine receptors (mAChRs)-induced LTD of NMDAR mediated synaptic transmission [34]. Knocking down PSD-95 and replacement with PSD-95 mutants lacking the SH3 domain blocked mAchR agonist-induced LTD of NMDAR EPSCs due to the disruption of interaction with hippocalcin. This effect can also be dissociated from the effects of PSD-95 on AMPAR and NMDAR EPSCs. Thus, several lines of evidence showed that effects of PSD-95 on basal synaptic transmission and several forms of synaptic plasticity can be dissociated, presumably because different domains and interaction sites are differentially involved in these processes.

\section{Homeostatic plasticity}

Homeostatic plasticity acts to stabilize the neuronal activity upon perturbations [35]. In the dissociated neuronal culture system, when synaptic activity is chronically blocked with TTX, synaptic AMPAR responses are elevated to compensate the lack of activity; whereas when neuronal activity is chronically elevated with GABAR blocker bicuculline, synaptic AMPAR responses are decreased. This experimental observation, named as synaptic scaling, has been used as a model for homeostatic plasticity. The first indication of the involvement of PSD-95 in homeostatic plasticity came from the study from dissociated cortical culture work, in a study demonstrating that levels of PSD-95 are dynamically regulated with chronic activity modulation [36]. Furthermore, the phosphorylation of S295 in PSD-95 can be regulated by chronic activity manipulation [27]. With chronic treatment of TTX, which scales up synaptic AMPAR responses, S295 phosphorylation is upregulated, presumably promoting synaptic localization of PSD-95. In contrary, chronic treatment of bicuculline causes opposite effects. Synaptic translocation of PSD-95 can be regulated by brain-derived neurotrophic factor (BDNF) that has been implicated in LTP and synaptic scaling [37]. These correlative observations suggest that regulation of PSD-95 may contribute to synaptic 
scaling. However, direct test on whether changes in PSD-95 levels and phosphorylation states of PSD-95 mediate homeostatic changes of synaptic AMPAR responses is lacking.

\section{Other PSD-MAGUKs and plasticity}

Evidence of the involvement of PSD-MAGUKs in synaptic plasticity first came from studies on genetically mutated animals. Among four family members, genetic deletion of PSD-95, PSD-93 and SAP102 have all shown deficit in a variety of hebbian type synaptic plasticity [14] [38*] [18]. SAP97-null animals are embryonic lethal, and studies on conditional knockout have not shown deficit in NMDAR-dependent LTP paradigm [39]. Table 1 compares the outcome in plasticity from PSD-MAGUK mutant mice. In this section, I will review studies on the involvement of PSD-93, SAP102, and SAP97 in synaptic plasticity in comparison to PSD-95, and discuss the possible functional diversities among different PSDMAGUKs.

\section{PSD-93}

Previous studies suggest that the role of PSD-95 and PSD-93 in regulating basal synaptic AMPAR function is overlapping [11]. The expression profiles throughout development are similar as well. In rodents, PSD-95 and PSD-93 express at low level early during development, and start to increase the expression from postnatal 10 days until reaches high levels in the adulthood (6 months) [40]. Although the phenotypes on basal transmission by regulating either PSD-95 or PSD-93 levels are similar, the outcome on synaptic plasticity is dramatically different. While PSD-95 knockout animals exhibit an enhancement of LTP and deficit in LTD, PSD-93 animals, however, showed a decrease of LTP in several paradigms including spike timing dependent plasticity [18]. It is unknown what causes the opposite effects on synaptic plasticity mediated by PSD-95 and PSD-93. Combined with previous studies on PSD-95, it is possible that PSD-95 and PSD-93 scaffold different protein complexes; therefore influence the outcome of synaptic plasticity differently. It has been hypothesized that PSD-95 and PSD-93 may be localized to different synapses, raising the possibility that synapses from the same cell may exhibit different plasticity properties given which protein is predominantly expressed $[11,18]$. There are six splice isoforms of PSD-93 that differ in the N-terminal region, much more diverse compared to other PSD-MAGUKs [41]. The cellular distribution, and the how these different splice isoforms regulate basal synaptic transmission and plasticity remain unknown. Understanding the functional diversity of these splice isoforms will provide important information in the diversity of glutamatergic synaptic transmission.

\section{SAP97}

Predominant SAP97 isoform contains an L27 domain in the N-terminal region ( $\beta$-isoform) different from the predominant PSD-95 isoform that has a palmitoylation signal in the $\mathrm{N}$ terminal region ( $\alpha$-isoform) [42,43*]. Unlike PSD-95, which interacts with AMPARs through direct binding to the transmembrane AMPAR regulatory proteins (TARPs) [23,44], SAP97 binds directly the AMPAR subunit GluR1 [45,46]. Studies on basal transmission showed that overexpression of SAP97 has little effect on synaptic AMPAR and NMDAR current, while others have shown a slight increase in both $[23,42,43]$. When expressed in the absence of endogenous PSD-95, however, it can rescue the decrease of AMPAR EPSCs caused by the loss of PSD-95. Interestingly, this rescue depends on NMDAR and CaMK activity, suggesting the involvement of SAP97 in the LTP signaling pathway[43*]. Studies have shown that acute knockdown of SAP97 causes deficit in LTP [42]. However, when tested in a knockout mouse line, LTP appears to be normal [39]. This apparent controversy suggested that SAP97 may play a regulatory role in LTP, and is not an essential component in LTP pathway. Alternatively, the absence of SAP97 through development (in the Nestin- 
cre crossed flx-SAP97 mouse line), other proteins can compensate the loss of SAP97 in LTP.

\section{SAP102}

SAP102 starts to express early during development, and its expression stays stable throughout the adulthood [40]. In comparison, the expression of PSD-95 starts from postnatal day 10 and increases throughout development until adulthood. Comparing to PSD-95, SAP102 has an unstructured N-terminal region. In mature neurons, SAP102 is highly mobile compared to PSD-95 [47]. During development, PSD-95 becomes enriched in the PSD [40]. Consistent with this observation, manipulating SAP102 in relatively mature neurons has no effect on AMPAR EPSCs, whereas manipulating SAP102 early in the development decreases AMPAR EPSCs significantly [48]. The developmental profile change between SAP102 and PSD-95 also coincides with the time course of NR2Acontaining NMDAR enrichment at the synapse, replacing NR2B-containg NMDARs that express predominantly during early development [40]. Changes in synaptic NR2A vs NR2B containing NMDARs have been proposed to be a mechanism for modulate plasticity [49]. Original biochemical data suggests that SAP102 preferentially interacts with NR2A containing NMDARs, whereas PSD-95 preferentially interacts with NR2B containing NMDARs [40]. This idea is further supported by functional analysis where PSD-95 mutant animals have slower NMDAR mediated synaptic current kinetics (i.e. NR2B containing prone) [17], whereas overexpression of PSD-95 accelerates NMDAR kinetics (NR2A prone) [48]. However, recent studies have shown that PSD-95, PSD-93 and SAP102 share similar affinity to NR2A vs NR2B subunits in mature animals [50]. It is likely that this interaction between PSD-MAGUKs and different NR2 subunits is regulated during development, and at different developmental stages, they exhibit different interaction affinity.

Studies in SAP102 knockout animals showed that lack of SAP102 has no effect on basal transmission and presynaptic function, but causes the enhancement both in high frequency induced LTP and spike timing dependent LTP [38*]. This phenotype is similar to that of PSD-95 mutant mice. Interestingly, in both of the deletion mutant lines, the counter part of the pair is upregulated, suggesting a compensatory mechanism among PSD-MAGUKs, possibly for the maintenance of basal synaptic transmission. However, further studies suggest that the signaling pathways responsible for enhanced LTP are different in these two mutant mouse lines. In SAP102 null mice, inhibiting the ERK signaling pathway can block the enhancement of LTP, whereas the enhancement of LTP in PSD-95 mutant mice is ERKpathway independent $\left[38^{*}, 51\right]$. These results suggest that although PSD-95 and SAP102 possibly share similar effect of negatively regulating LTP, the detailed mechanisms may be different. Both of the genetically modified mouse lines are constitutive knockout throughout the whole brain and in both excitatory and inhibitory neurons, how lack of PSD-95 and SAP102 affects the abnormality in synaptic plasticity during development, and in inhibitory neurons is unknown. Further studies with more temporal- and cell-type specific manipulations should provide more information in how SAP102 is involved in synaptic plasticity.

\section{Conclusion}

The role of PSD-95 in regulating synaptic AMPAR functions has been established with overwhelming evidence. In this review, I summarized the recent studies supporting that PSD-95 not only forms structural scaffold for anchoring AMPARs at the PSD, but also serves as the signaling scaffold to bridge the intracellular signaling complex the NMDARs. The effects of PSD-95 on regulating basal synaptic AMPAR function and plasticity can be separated. Furthermore, the dynamics of PSD-95 is highly regulated during synaptic plasticity, and this likely contributes to the expression and termination of synaptic plasticity. 
Emerging data from knockout animals and molecular manipulations suggest that PSDMAGUKs are functionally diverse in terms of regulating synaptic plasticity. Future studies will be forthcoming to gain some insight on how this diversity is achieved, and to what extent PSD-MAGUKs contribute to orchestrating the signaling cascades for the various types of synaptic plasticity at glutamatergic synapses.

\section{Acknowledgments}

I apologize, due to the space limitation; many excellent publications could not be cited. I thank Oliver Schluter and $\mathrm{Xu}$ lab members including Patrick Redman, Kendrick Jones and Mingna Liu for helpful comments. This work is supported by the grant from the National Institute of Mental Health (MH080310).

\section{Reference and recommended reading}

* of special interest

** of outstanding interest

1. Kim E, Sheng M. PDZ domain proteins of synapses. Nat Rev Neurosci. 2004; 5:771-781. [PubMed: 15378037]

2. Montgomery JM, Zamorano PL, Garner CC. MAGUKs in synapse assembly and function: an emerging view. Cell Mol Life Sci. 2004; 61:911-929. [PubMed: 15095012]

3. Scannevin RH, Huganir RL. Postsynaptic organization and regulation of excitatory synapses. Nat Rev Neurosci. 2000; 1:133-141. [PubMed: 11252776]

4. Kristiansen LV, Beneyto M, Haroutunian V. Meador-Woodruff JH. Changes in NMDA receptor subunits and interacting PSD proteins in dorsolateral prefrontal and anterior cingulate cortex indicate abnormal regional expression in schizophrenia. Mol Psychiatry. 2006; 11:737-747. 705. [PubMed: 16702973]

5. Tarpey P, Parnau J, Blow M, Woffendin H, Bignell G, Cox C, Cox J, Davies H, Edkins S, Holden S, et al. Mutations in the DLG3 gene cause nonsyndromic X-linked mental retardation. Am J Hum Genet. 2004; 75:318-324. [PubMed: 15185169]

6. Jamain S, Quach H, Betancur C, Råstam M, Colineaux C, Gillberg IC, Soderstrom H, Giros B, Leboyer M, Gillberg C, et al. Mutations of the X-linked genes encoding neuroligins NLGN3 and NLGN4 are associated with autism. Nat Genet. 2003; 34:27-29. [PubMed: 12669065]

7. Bienvenu OJ, Wang Y, Shugart YY, Welch JM, Grados MA, Fyer AJ, Rauch SL, McCracken JT, Rasmussen SA, Murphy DL, et al. Sapap3 and pathological grooming in humans: Results from the OCD collaborative genetics study. Am J Med Genet B Neuropsychiatr Genet. 2009; 150B:710-720. [PubMed: 19051237]

8. Berkel S, Marshall CR, Weiss B, Howe J, Roeth R, Moog U, Endris V, Roberts W, Szatmari P, Pinto D, et al. Mutations in the SHANK2 synaptic scaffolding gene in autism spectrum disorder and mental retardation. Nat Genet. 2010; 42:489-491. [PubMed: 20473310]

9. Durand CM, Betancur C, Boeckers TM, Bockmann J, Chaste P, Fauchereau F, Nygren G, Rastam M, Gillberg IC, Anckarsäter H, et al. Mutations in the gene encoding the synaptic scaffolding protein SHANK3 are associated with autism spectrum disorders. Nat Genet. 2007; 39:25-27. [PubMed: 17173049]

10. Chen X, Vinade L, Leapman RD, Petersen JD, Nakagawa T, Phillips TM, Sheng M, Reese TS. Mass of the postsynaptic density and enumeration of three key molecules. Proc Natl Acad Sci USA. 2005; 102:11551-11556. [PubMed: 16061821]

$11 * *$. Elias GM, Nicoll RA. Synaptic trafficking of glutamate receptors by MAGUK scaffolding proteins. Trends Cell Biol. 2007; 17:343-352. A very good summary of the roles of different PSD-MAGUKs in regulating AMPAR trafficking at different synapses and at different developmental stages. [PubMed: 17644382]

12. Yoshii A, Sheng MH, Constantine-Paton M. Eye opening induces a rapid dendritic localization of PSD-95 in central visual neurons. Proc Natl Acad Sci USA. 2003; 100:1334-1339. [PubMed: 12552131] 
13. van Zundert B, Yoshii A, Constantine-Paton M. Receptor compartmentalization and trafficking at glutamate synapses: a developmental proposal. Trends Neurosci. 2004; 27:428-437. [PubMed: 15219743]

14* . Migaud M, Charlesworth P, Dempster M, Webster LC, Watabe AM, Makhinson M, He Y, Ramsay MF, Morris RG, Morrison JH, et al. Enhanced long-term potentiation and impaired learning in mice with mutant postsynaptic density-95 protein. Nature. 1998; 396:433-439. This paper is the first to demonstrate that PSD-95 is involved in synaptic plasticity using PSD-95 mutant mice as a model system. [PubMed: 9853749]

15. Yao WD, Gainetdinov RR, Arbuckle MI, Sotnikova TD, Cyr M, Beaulieu JM, Torres GE, Grant SG, Caron MG. Identification of PSD-95 as a regulator of dopamine-mediated synaptic and behavioral plasticity. Neuron. 2004; 41:625-638. [PubMed: 14980210]

16. Elias GM, Funke L, Stein V, Grant SG, Bredt DS, Nicoll RA. Synapse-specific and developmentally regulated targeting of AMPA receptors by a family of MAGUK scaffolding proteins. Neuron. 2006; 52:307-320. [PubMed: 17046693]

17. Béïque JC, Lin DT, Kang MG, Aizawa H, Takamiya K, Huganir RL. Synapse-specific regulation of AMPA receptor function by PSD-95. Proc Natl Acad Sci USA. 2006; 103:19535-19540. [PubMed: 17148601]

18** . Carlisle HJ, Fink AE, Grant SG, O’Dell TJ. Opposing effects of PSD-93 and PSD-95 on longterm potentiation and spike timing-dependent plasticity. J Physiol (Lond). 2008; 586:5885-5900. This paper showed that PSD-95 and PSD-93 mutant mice exhibit opposite defects in synaptic plasticity, strongly suggesting that they convey different functions in mediating synaptic plasticity. [PubMed: 18936077]

19**. Xu W, Schlüter OM, Steiner P, Czervionke BL, Sabatini B, Malenka RC. Molecular dissociation of the role of PSD-95 in regulating synaptic strength and LTD. Neuron. 2008; 57:248-262. This paper showed that the roles of PSD-95 in regulating basal synaptic transmission and plasticity are dissociable. The C-terminal SH3 and GK domains mediate protein-protein interactions important for LTD induction/expression. The dynamcis of PSD-95 is critical for LTD as well. [PubMed: 18215622]

20. Ehrlich I, Klein M, Rumpel S, Malinow R. PSD-95 is required for activity-driven synapse stabilization. Proc Natl Acad Sci USA. 2007; 104:4176-4181. [PubMed: 17360496]

21. Stein V, House DR, Bredt DS, Nicoll RA. Postsynaptic density-95 mimics and occludes hippocampal long-term potentiation and enhances long-term depression. J Neurosci. 2003; 23:5503-5506. [PubMed: 12843250]

22. Béique JC, Andrade R. PSD-95 regulates synaptic transmission and plasticity in rat cerebral cortex. J Physiol (Lond). 2003; 546:859-867. [PubMed: 12563010]

23. Schnell E, Sizemore M, Karimzadegan S, Chen L, Bredt DS, Nicoll RA. Direct interactions between PSD-95 and stargazin control synaptic AMPA receptor number. Proc Natl Acad Sci USA. 2002; 99:13902-13907. [PubMed: 12359873]

24* . Colledge M, Snyder EM, Crozier RA, Soderling JA, Jin Y, Langeberg LK, Lu H, Bear MF, Scott JD. Ubiquitination regulates PSD-95 degradation and AMPA receptor surface expression. Neuron. 2003; 40:595-607. This paper demonstrated that agonist-induced ubiquitination of PSD-95 can regulate AMPAR surface expression and may be a target to proteosomal degredation pathway that is critical for NMDAR-dependent LTD. [PubMed: 14642282]

25*. El-Husseini, AelD; Schnell, E.; Dakoji, S.; Sweeney, N.; Zhou, Q.; Prange, O.; GauthierCampbell, C.; Aguilera-Moreno, A.; Nicoll, RA.; Bredt, DS. Synaptic strength regulated by palmitate cycling on PSD-95. Cell. 2002; 108:849-863. This paper showed that agonist induced internalization of AMPARs requires depalmitoylation of PSD-95, suggesting that palmitate cycling on PSD-95 can regualate synaptic AMPAR levels and activity-dependent plasticity. [PubMed: 11955437]

26. El-Husseini, AelD; Bredt, DS. Protein palmitoylation: a regulator of neuronal development and function. Nat Rev Neurosci. 2002; 3:791-802. [PubMed: 12360323]

27* . Kim MJ, Futai K, Jo J, Hayashi Y, Cho K, Sheng M. Synaptic accumulation of PSD-95 and synaptic function regulated by phosphorylation of serine-295 of PSD-95. Neuron. 2007; 56:488502. This paper showed that phophorylation of S295 of PSD-95 is involved in multiple acitivitydependent paradigms including LTP, LTD and synaptic scaling. [PubMed: 17988632] 
28. Kuriu T, Inoue A, Bito H, Sobue K, Okabe S. Differential control of postsynaptic density scaffolds via actin-dependent and -independent mechanisms. J Neurosci. 2006; 26:7693-7706. [PubMed: 16855097]

29*. Steiner P, Higley MJ, Xu W, Czervionke B, Malenka R, Sabatini BL. Destabilization of the Postsynaptic Density by PSD-95 Serine 73 Phosphorylation Inhibits Spine Growth and Synaptic Plasticity. Neuron. 2008; 60:788-802. Using a combination of two-photon imaging and electrophysiology, this paper shows that the dynamics of PSD-95 is critical for structual and functional LTP. CaMKII phosphorylation is an important signaling event for controlling the dynamics of PSD-95 during LTP induction and expression. [PubMed: 19081375]

30. Tavalin SJ, Colledge M, Hell JW, Langeberg LK, Huganir RL, Scott JD. Regulation of GluR1 by the A-kinase anchoring protein 79 (AKAP79) signaling complex shares properties with long-term depression. J Neurosci. 2002; 22:3044-3051. [PubMed: 11943807]

31. Smith KE, Gibson ES, Dell' Acqua ML. cAMP-dependent protein kinase postsynaptic localization regulated by NMDA receptor activation through translocation of an A-kinase anchoring protein scaffold protein. J Neurosci. 2006; 26:2391-2402. [PubMed: 16510716]

32. Lu Y, Zhang M, Lim IA, Hall DD, Allen M, Medvedeva Y, McKnight GS, Usachev YM, Hell JW. AKAP150-anchored PKA activity is important for LTD during its induction phase. J Physiol (Lond). 2008; 586:4155-4164. [PubMed: 18617570]

33. Bhattacharyya S, Biou V, Xu W, Schlüter O, Malenka RC. A critical role for PSD-95/AKAP interactions in endocytosis of synaptic AMPA receptors. Nat Neurosci. 2009; 12:172-181. [PubMed: 19169250]

34. Jo J, Son GH, Winters BL, Kim MJ, Whitcomb DJ, Dickinson BA, Lee YB, Futai K, Amici M, Sheng M, et al. Muscarinic receptors induce LTD of NMDAR EPSCs via a mechanism involving hippocalcin, AP2 and PSD-95. Nat Neurosci. 2010; 13:1216-1224. [PubMed: 20852624]

35. Turrigiano G. Homeostatic signaling: the positive side of negative feedback. Curr Opin Neurobiol. 2007; 17:318-324. [PubMed: 17451937]

36. Ehlers MD. Activity level controls postsynaptic composition and signaling via the ubiquitinproteasome system. Nat Neurosci. 2003; 6:231-242. [PubMed: 12577062]

37. Yoshii A, Constantine-Paton M. BDNF induces transport of PSD-95 to dendrites through PI3KAKT signaling after NMDA receptor activation. Nat Neurosci. 2007; 10:702-711. [PubMed: 17515902]

38*. Cuthbert PC, Stanford LE, Coba MP, Ainge JA, Fink AE, Opazo P, Delgado JY, Komiyama NH, O'Dell TJ, Grant SG. Synapse-associated protein 102/dlgh3 couples the NMDA receptor to specific plasticity pathways and learning strategies. J Neurosci. 2007; 27:2673-2682. This paper shows that although SAP102 and PSD-95 mutant mice have similar outcome in terms of enhanced LTP, the underlying signaling pathways may be different. [PubMed: 17344405]

39. Howard MA, Elias GM, Elias LA, Swat W, Nicoll RA. The role of SAP97 in synaptic glutamate receptor dynamics. Proc Natl Acad Sci USA. 2010

40. Sans N, Petralia RS, Wang YX, Blahos J, Hell JW, Wenthold RJ. A developmental change in NMDA receptor-associated proteins at hippocampal synapses. J Neurosci. 2000; 20:1260-1271. [PubMed: 10648730]

41. Parker MJ, Zhao S, Bredt DS, Sanes JR, Feng G. PSD93 regulates synaptic stability at neuronal cholinergic synapses. J Neurosci. 2004; 24:378-388. [PubMed: 14724236]

42. Nakagawa T, Futai K, Lashuel HA, Lo I, Okamoto K, Walz T, Hayashi Y, Sheng M. Quaternary structure, protein dynamics, and synaptic function of SAP97 controlled by L27 domain interactions. Neuron. 2004; 44:453-467. [PubMed: 15504326]

43*. Schlüter OM, Xu W, Malenka RC. Alternative N-terminal domains of PSD-95 and SAP97 govern activity-dependent regulation of synaptic AMPA receptor function. Neuron. 2006; 51:99111. Using a molecular replacement strategy, the authors demonstrated the isoform-dependent functional difference of PSD-95 and SAP97 in regulating synaptic AMPAR-mediated transmission. L27-containing isoforms regulate synaptic AMPARs in an activity dependent way and also depends on the endogenous palmitoylation isoform. [PubMed: 16815335] 
44. Chen L, Chetkovich DM, Petralia RS, Sweeney NT, Kawasaki Y, Wenthold RJ, Bredt DS, Nicoll RA. Stargazin regulates synaptic targeting of AMPA receptors by two distinct mechanisms. Nature. 2000; 408:936-943. [PubMed: 11140673]

45. Sans N, Racca C, Petralia RS, Wang YX, McCallum J, Wenthold RJ. Synapse-associated protein 97 selectively associates with a subset of AMPA receptors early in their biosynthetic pathway. $\mathrm{J}$ Neurosci. 2001; 21:7506-7516. [PubMed: 11567040]

46. Leonard AS, Davare MA, Horne MC, Garner CC, Hell JW. SAP97 is associated with the alphaamino-3-hydroxy-5-methylisoxazole-4-propionic acid receptor GluR1 subunit. J Biol Chem. 1998; 273:19518-19524. [PubMed: 9677374]

47. Zheng CY, Petralia RS, Wang YX, Kachar B, Wenthold RJ. SAP102 is a highly mobile MAGUK in spines. J Neurosci. 2010; 30:4757-4766. [PubMed: 20357126]

48. Elias GM, Elias LA, Apostolides PF, Kriegstein AR, Nicoll RA. Differential trafficking of AMPA and NMDA receptors by SAP102 and PSD-95 underlies synapse development. Proc Natl Acad Sci USA. 2008; 105:20953-20958. [PubMed: 19104036]

49. Yashiro K, Philpot BD. Regulation of NMDA receptor subunit expression and its implications for LTD, LTP, and metaplasticity. Neuropharmacology. 2008; 55:1081-1094. [PubMed: 18755202]

50. Al-Hallaq RA, Conrads TP, Veenstra TD, Wenthold RJ. NMDA di-heteromeric receptor populations and associated proteins in rat hippocampus. J Neurosci. 2007; 27:8334-8343. [PubMed: 17670980]

51. Opazo P, Watabe AM, Grant SG, O'Dell TJ. Phosphatidylinositol 3-kinase regulates the induction of long-term potentiation through extracellular signal-related kinase-independent mechanisms. J Neurosci. 2003; 23:3679-3688. [PubMed: 12736339] 


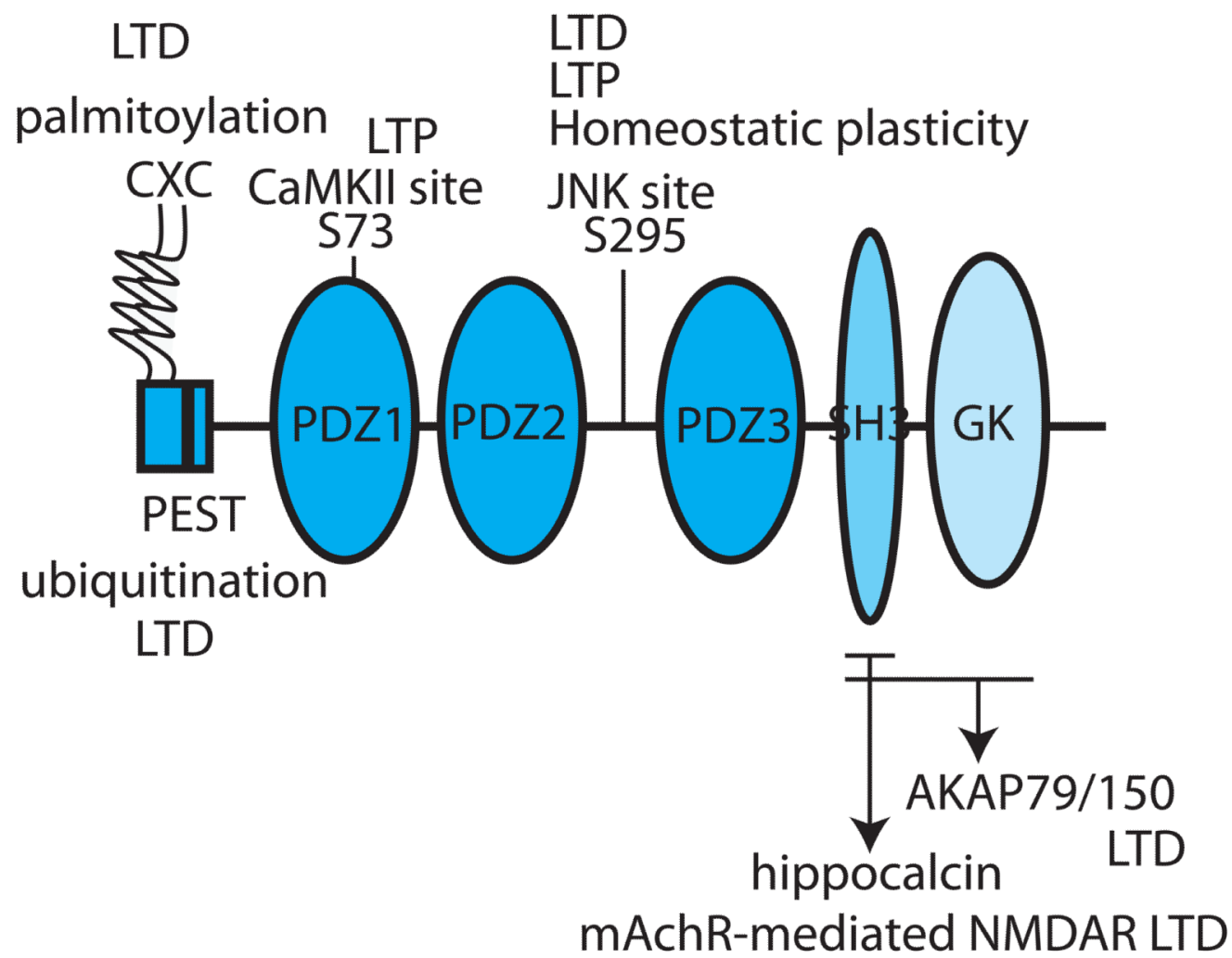

Figure 1.

Schematic diagram of sites in PSD-95 involved in synaptic plasticity. PSD-95 is involved in synaptic plasticity in several scenarios. Palmitoylation, ubiquitination and phosphorylation of S295 have been proposed to be involved in regulating activity-dependent synaptic cycling of PSD-95 that influence the anchoring of synaptic AMPARs at the synapse during LTD $[24,25,27]$. S295 is also thought to be involved in LTP and homeostatic plasticity. The functions of PSD-95 in regulating basal synaptic transmission and plasticity are dissociable. Three lines of evidence show that mutants that do not have impact on the function of PSD-95 in regulating basal synaptic transmission can influence synaptic plasticity. Phosphorylation of S73 by CaMKII is involved in regulating the dynamics of PSD-95 during LTP, and thought to be important for structural and functional plasticity [29]. SH3 domain mediated interaction with hippocalcin is important in mediating $\mathrm{mAchR}$-dependent LTD of NMDARs [34]. The interaction through SH3-GK domain, presumably with AKAP150/79 is thought to be important for mediating LTD [19]. Therefore, PSD-95 has multifaceted effects on synaptic transmission and plasticity. 
Table 1

Phenotypes of synaptic function and synaptic plasticity of PSD-MAGUK mutant mice

\begin{tabular}{lllll}
\hline & PSD-95 $[\mathbf{1 4 , 1 8}]$ & PSD-93 [18] & SAP97 [39] & SAP102 [38] \\
basal transmission & decreased/not affected & not affected & not affected & not affected \\
Paired pulse ratio & enhanced & enhanced & n.a. & normal \\
High frequency stim-LTP & enhanced & slightly decreased & n.a. & enhanced \\
LTP saturation level & enhanced & n.a. & n.a. & n.a. \\
Theta burst stim-LTP & enhanced & impaired & n.a. & n.a. \\
5Hz-LTP (threshold) & enhanced & n.a. & n.a. & enhanced \\
pairing LTP & enhanced & n.a. & not affected & n.a. \\
Spike-timing-dependent-LTP 1AP pair $10 \mathrm{~Hz}$ & enhanced & normal & n.a. & enhanced \\
Spike-timing-dependent-LTP burst pair $10 \mathrm{~Hz}$ & slightly enhanced & impaired & n.a. & normal \\
Low frequency stim-LTD & deficient & normal & n.a. & n.a. \\
\hline
\end{tabular}

Curr Opin Neurobiol. Author manuscript; available in PMC 2012 April 1. 